\title{
Integration of informal music technologies in secondary school music lessons
}

\author{
Dan Stowell and Simon Dixon
}

May 10, 2011

\begin{abstract}
Technologies such as Youtube, mobile phones and MP3 players are beginning to be integrated into secondary school music in the UK. At the same time, the gap between formal and informal music learning is being bridged by the incorporation of students' preferred music into class activities. We conducted an ethnographic study in two secondary schools in London, investigating the roles of technology in the negotiation of musical concepts in music classes. From this, we report some observations on the relation between formal/informal and authorised/unauthorised activities in class, and some specific observations on the role of Youtube, mobile phones and MP3 players in the class context. In the lessons we observed, these technologies functioned as part of a richly multimodal ecosystem of technologies, combining aspects formal and informal use. This carries implications for how we plan for the use of technology in the delivery of music education.
\end{abstract}

\section{Introduction}

The use of digital technologies in the music classroom is a live issue. Internet video, mobile phones and MP3 players have seen enthusiastic take-up by teenagers and are now widespread [Nielsen Company, 2009]. Meanwhile, recent research across English secondary schools raised issues such as the lack of integration of digital technologies with other classroom resources, and questions of teachers' continuing professional development [Savage, 2010]. There has been a move to bridge the gap between the technology of the music classroom and that of the wider world [Savage, 2010, and citations within], The 2011 Henley Review of Music Education in England recommended that "further work should be undertaken to develop a national plan for the use of technology in the delivery of Music Education - and to ensure that the workforce is up-to-date with latest developments" [Henley, 2011, p. 30]. More specifically, it recommended studying the use of technology for music education in rural communities (with no explicit motivation, though presumably referring to communication technologies), and "new methods of creating music that embrace technological innovation" (ibid.). 
Hand in hand with technological developments has been the move to bridge the gap between "formal" and "informal" music practices for the benefit of music learning [Folkestad, 2005, Green, 2008, Wright, 2010]. "Informal" practices include those used in learning to make music in non-institutional contexts, but also those used socially in sharing music with friends. The work of Green [2008] represents an important movement in music pedagogy by strengthening connections with and recognition of informal music-making practices. However, Green [2010] argues that "[w]e would benefit from further careful philosophical discussions of the different possible meanings and uses of the terms formal, informal and non-formal" (p91).

In the present paper we contribute to the issues around formal/informal practices and the incorporation of new technologies into the classroom, not as educationalists but from the perspective of music technologists. Our own research is situated in the field of music information retrieval (MIR) [Orio, 2006], a discipline which studies the many ways that information can be automatically extracted from music, and how it can be presented for effective search/browsing and musical understanding. We wanted to explore how such MIR technologies might find their place in the music classroom; hence we conducted an ethnographic study of current technologies in the classroom (high- and low-tech), and how they related to each other and to the negotiation of musical concepts. Those of our findings which bear upon the MIR community have been reported elsewhere [submitted]; here we present those of our findings which relate to current educational topics of the adoption/integration of digital technologies in music education, and of the relation between formal and informal practices in the classroom.

In this research our focus is not on a specific curriculum or age, but on the interaction of technologies with music teaching and learning, broadly across Key Stages (KSs) 3 and 4. Hence our study involves a heterogeneous set of class groups from two schools, and draws out broad themes relating to current technology and secondary schools.

After describing our setting and methods, we present themes which emerged from our ethnography. We first discuss the relationship between authorised, unauthorised and casual activity - describing a model which bears upon the integration of technologies more associated with informal practices, such as student mobile phones. We then discuss the position of mobile phones and MP3 players in classroom interactions, the use of Youtube, and the interactions between various high- and low-technologies.

\subsection{Setting and methods}

We chose to use an ethnographic approach, so as to elicit a rich thick description of the way music-related ideas are used and relate to each other in a specific context. The sensitising questions used to guide the ethnography were:

What music-related concepts do teachers and students negotiate in music classes? 
How do they achieve this - with, and without, technology?

(The present paper mainly concerns issues raised around the latter question.)

The study was conducted in music lessons at two secondary schools in London. The two schools were selected after contacting a small selection of comprehensive secondary schools in the London area with music programmes.

- School A was located in East London, with around 1200 students. The school had $\approx 65 \%$ of students receiving free school meals; $\approx 15 \%$ having special educational needs; and $\approx 50 \%$ obtaining five or more $\mathrm{A}^{*}$-C GCSEs and equivalent in 2010. The music department had six full-time music teachers, plus peripatetic teachers. It was a participating department in the Paul Hamlyn Foundation "Musical Futures" scheme [Hallam et al., 2008].

- School B was located in West London, with around 1000 students. The school had $\approx 25 \%$ of students receiving free school meals; $\approx 15 \%$ having special educational needs, and $\approx 30 \%$ obtaining five or more $\mathrm{A}^{*}$-C GCSEs and equivalent in 2010. The performing arts department had two full-time music teachers, plus peripatetic teachers.

Each school ran a two-weekly timetable, meaning the visits (over the period November 2010 - March 2011) typically covered about six lessons of each particular class. Various KS 3 and 4 lessons were included in the study, according to availability. These included Music GCSE lessons in both schools, plus Music Technology BTEC lessons in School B, and a Year 8 music performance project in School A.

Observations were conducted by one observer with notebook and pen; to minimise disruption and facilitate access, video/audio recording were not used. Analysis of the fieldnotes was conducted as described in Emerson et al. [1995] using focused coding followed by thematic analysis. In the following, all personal names of teachers/students are pseudonyms.

\section{Classroom dynamics: authorised, unauthorised and casual activity}

Our first theme arising from the data analysis concerns the dynamics of what activity is authorised and unauthorised in class, and how this is negotiated. This is not the same issue as the formal/informal distinction, but it is related: in a music lesson there are often moments of informal music - for example a group of friends singing a current pop song together - and such activity could be incorporated into the lesson, or could be disallowed. The management of this boundary is also relevant when considering specific technologies, such as whether or not mobile phones are permitted.

From our observations of the everyday detail of interactions in music lessons, a strong pattern emerged: there is almost never a clear division between what 


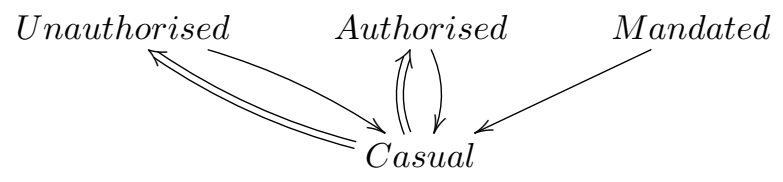

Figure 1: Movement between different modes of activity. The double-thickness arrows are changes occurring through explicit status negotiation.

might be formal and informal modes of activity, or between activity that might be authorised by the teacher and that which might not. A large proportion of students' time is spent in activities whose status is ambiguous: for example engaging in exploratory or creative tasks, or conversations with others. When the status is negotiated between teacher and student, it is almost never based on a priori categories but emerges from the negotiation of many very local factors - often unpredictable in advance.

There are of course exchanges with the teacher in which the authorised/unauthorised status emerges, and often a teacher will instruct students to do certain things (we will call this "mandated" activity) - but students' activities evolve quickly through their interaction with learning materials, tools and other people, and very quickly progress beyond the most recent point of negotiation. So most of the time students are engaged in what we will refer to as "casual" activity - not meaning off-topic activity but activity whose authorised/unauthorised status is ambiguous, but could be crystallised by teacher/student negotation. The flow between these modes of activity is depicted in Figure 1.

As one brief illustration, the following excerpt is one of many in which students spontaneously sing together, in a way not directly related to a class task but for enjoyment. The class is a Year 10 class of about a dozen male students at School B:

The students had mostly sat in the chairs around the edge of the room, at the computers. The teacher (Lauren) said "circle!" to get them to arrange their chairs pointing inwards, in a circular arc nearer the middle of the room. Lauren was still sorting out folders and students, while the students were talking among themselves about various things. Two or three of the students started doing something where they would sing someone's name in a close-harmony-type chord. One would sing "Simoooooooooooon" and another would join in "Simooon" and another on top of that. They did this with a few names.

Lauren: I like how that just turned into like harmony, that's like [.]

it's like barbershop quartet [.] right wait stop

[The students sat around her stop talking/singing]

Lauren: Right do it again

*: What are we gonna do?

*: Garyyyyyyyyyyyyyyyyyyy

*: $\quad$ Garyyyyyyуyуyуyуyy

*: $\quad$ Garyyyyyyyyyy 


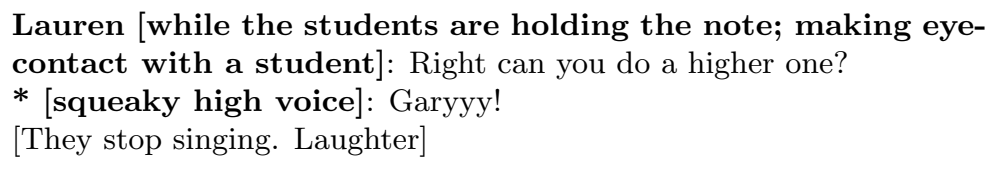

Here the teacher co-opts the situation to encourage the students to explore singing in a tiny informal activity, and connects it with the idea of a barbershop quartet (possibly why she asks a fourth student to join in). The students' attitude to singing is here playful and social, sitting outside specifically evaluated tasks. The teacher authorises the activity and directs it. In other superficially similar instances, moments of singing might be either unauthorised or left ambiguous. There is no a priori status of such informal activities, but teachers and students are able to negotiate the status as needed.

We emphasise that our assertion of this pattern is not just a relativist refusal to acknowledge a difference between students following and straying from the lesson plan. Firstly, it is not just the teacher who decides what is authorised, but it is often negotiated between teacher and student. Nor is it only activity specified by the teacher that is authorised. Nor is the decision based on general properties such as the mode employed: for example sometimes a visit to Youtube is authorised or mandated, sometimes teachers disallow it.

More fundamentally, though, students' actions evolve quickly in interaction with many things around them (socially and physically), and even if one particular action is authorised/unauthorised by a teacher's intervention, the students' activity very quickly moves beyond that specific action. Further, students are often assigned open-ended and often creative tasks, which is important for their learning and their engagement in learning; in such conditions, actions or discussions which have only tangential relation to the formal curriculum topic are very likely, and their authorised/unauthorised status may emerge later after discussion with a teacher, or may never be stated.

The next excerpt shows a rather different classroom context, yet the same issues emerge of technological freedoms and constraints, student exploratory activity, and negotiation between teacher and students about the status of different activities. It is from a Year 10 lesson at School A, in which the main activity is to use a music sequencer to create a beat pattern:

The teacher (Evan) was sitting at the main classroom computer demonstrating to the class something using Logic Pro. There were about 20 students in the room, sitting in chairs at the computer desks but turned round to watch what Evan was doing (projected on the screen at the front of the room).

Evan: [...] so you put your bass drums where you want them [Evan clicks in Logic Pro window, then plays back a beat, slightly different to the one he just played before]

Evan: and you can add in some other sounds

[Evan clicks in some different rows on the screen, adding a couple of sound effects to the loop that's playing back]

Evan talked this through a bit more, among other things telling the class to 
"keep it simple". As the beat played back he stood up and went to the projected screen, pointing at the boxes which he had clicked to turn on.

Evan: Hard to see it on this blue screen, hard to see this blue on the screen, but I've put a hihat on each one here [points] so use hihat kick and snare are the basic things you need. [Going to sit back at the computer:] OK so I'm gonna unlock your screens.

Evan sat at the computer and clicked something, and the screens of the students' computers briefly flashed up a big padlock image before clearing to reveal their normal desktops. I hadn't noticed that the screens were locked, but they must have been blank up until that point.

The students loaded up Logic Pro as instructed, getting to a beat sequencer screen with a predefined pattern loaded into it.

Rianna: Sir do we delete what's there already?

Evan: Yeah. [Announcing to all]: Just delete what's there already

Rianna: Sir how dyou delete?

Evan: You just click and drag

[Evan goes over to Rianna and demonstrates delete, using the mouse.]

$[\ldots]$

Evan: Get started with the bass drum

Rianna: Sir the bass what? [.] I started with the [as if an unfamiliar name:] main kit.

A little bit later Evan was leaning over Shanice demonstrating what to do on her screen:

Evan: What kind of drumkit you got? [.] Drum and bass?

Shanice: Yeah

Gina: Sir how dyou do a [.] beat

Evan [to Shanice]: So you can put a snare on the offbeats

Gina: Sir how dyou make it do a beat

Evan [to Gina]: You click in there

Gina: Just click wherever

Evan: Yeah well you [.] see if you can work out where to put it, to

make a good beat

Gina: So we just make a beat?

Evan: Yeah

After Evan had moved on from this group, Shanice had done something in the sequencer and had passed her headphones to Ashley to listen to the results. Gina looked over at Shanice's screen:

Gina: That's not gonna work

Ashley [listening on headphones]: No sounds good

Gina: Is it good? Save it if it sounds good

[Ashley is nodding appreciatively to the beat, grinning]

Gina: She's written her name

Shanice: No I've written S, H, then murrrrrrrrrr

On Shanice's screen the pattern in the sequencer did look a bit like an S, a H and then some squiggle.

Evan was walking around the class. He talked to some of the students as he did, then to Shanice: 
Evan: There that's far too busy.

Shanice: Sir I like it

Evan: No it's far too busy. Delete some of that.

Evan reached over and deleted most of the sequenced notes for her. Then he went over to Rianna, and talked her through adding notes to the sequencer, helping her to choose notes and inputting what looked like a very regular beat (one element playing on every eighth note, one on every quarter, etc), very different from the pattern that had been on Shanice's screen. I noticed that Gina had taken inspiration from Shanice and had written her name in the sequencer screen, quite clearly this time. She was listening through to the sound it made and nodding. She turned to Shanice:

Gina: Listen to that

[Shanice takes the offered headphones and listens.]

Gina [to Evan]: Sir that's my beat, I've done there.

Evan didn't respond - he was wearing Rianna's headphones and looking at her screen.

Jasmine (who was sitting at a computer on the far side of the room) stood up and walked around a bit. She came over to Gina and took the proffered headphones to listen to Gina's beat.

Gina: That's my beat. Sir that's my beat.

Jasmine: It's quite good actually.

Evan: Let's have a listen. [He accepts the headphones and listens a bit.] It's probably too busy. Have a listen to Rianna's [points at Rianna's screen]

Jasmine [going back to her seat]: I'm gonna write my name in mine.

Shortly after this, Evan went back to the main computer and clicked to reactivate the screen lock. As the big padlock image appeared on the students' computers they shouted "Aww!" with a tone of surprise and anger.

The technological means of allowing/preventing activity (the screen lock) used in this excerpt is, like the net filter, a relatively blunt instrument, though this time under the active control of the teacher and used to direct attention towards the teacher at specific points in the lesson.

However, the more subtle interaction is around what kind of activities with the sequencer are allowed or disallowed. In this lesson the students are set a creative task, with apparent freedom apart from the advice to "keep it simple". The students who write their names into the sequencer screen are exploring the software in what appear to be actions intended to fulfil the task (they aren't attempting to subvert the lesson), and create patterns that sound interesting to them. However, the loops that these students find interesting to make are clearly not the loops that the teacher wants them to produce, although they are nominally in a position of creative freedom. The teacher progressively clarifies the types of pattern expected, marking some rhythm patterns as unauthorised by judging them (from visual appearance) as "too busy", by deleting one of them, and by indicating another student's work as a better example. 
The circulation of the idea of making a rhythmic pattern from one's name shows a small-scale example of informal learning occurring in class. The excerpt shows a tension between this and the intentions of the teacher - note however that we selected this excerpt because the tension leads to explicit discussion which is useful for our exposition. More generally, the school (and the teacher) made wide use of approaches inspired by informal learning considerations.

Both the excerpts presented in this section illustrate occasions where explicit work is done to negotiate the boundary between authorised and unauthorised, regarding student activity that has informal aspects. However, such negotiation is relatively rare in actual classroom interactions; imbetween these occasions, much activity occurs whose status is ambiguous (we have labelled this "casual" activity). In the next section, we will see similar issues surrounding mobile phones and MP3 players, with specific instances of negotiation but also periods of ambiguity.

Some of the educational debate in recent years has considered the relation of informal musics to music education, and how they can usefully be brought into the classroom. Our observations offer a slightly different perspective on this. When one looks in detail at what happens in a music lesson, the distinction between formal and informal types of activity (the position on Folkestad [2005]'s axis) diminishes, since the majority of activities have no explicit status and almost all activities evolve quickly due to the interactions of participants.

In the following two sections we will consider some specific technologies which we observed to have an interesting role in classroom interactions. They are technologies whose role is more commonly associated with social and informal music listening.

\section{$3 \quad$ Mobile phones and MP3 players}

Our analysis found themes emerging around mobile phones and MP3 players, in particular relating to the authorised/unauthorised status questions discussed above. These devices are a popular vehicle for music audio/video [Nielsen Company, 2009], and they are generally the students' own, brought into the school rather than provided by the school; so they might be considered a key route by which social and informal musics might find their way into the music classroom.

Both the schools studied had official bans on student use of mobile phones. School B displayed this sign prominently in the entrance hall:

Mobile phones are

not allowed in

[School B]

[icon - a phone in a red circle with a red crossthrough]

If they are seen

they will be

confiscated!! 
However, despite the official prohibition, phones were quite often brought out for various purposes in both schools, for class-related and more social purposes. The following excerpt is from a Year 8 lesson in School A, in which the teacher (Andy) was facilitating a group of six students in a small studio room, learning to play together as a band:

From time to time the students would talk about what "other" song they were going to play, apart from the one they had been practising.

Brittany: I wanna do a different song.

Keisha: [...] on my phone

Andy: Oh, you wanna play a new song on your phone? Not right

now.

[...later...]

Andy: I can give you two minutes if you wanna choose your next song.

[To Keisha:] Get your phone out.

Keisha got her phone out. Someone suggested holding the mic to the phone so she did that, after starting the track playing.

Andy: One in ten chance it's a rock song.

The track played, audible over the studio speakers, "Best Behaviour" by NDubz. There were some drums, synth strings, piano and some other sounds, plus a male vocal. The drum line included some fairly rapid hi-hat playing.

Andy: How do you play that bit on the drums?

Nashida: I can't play that

Andy: Yeah you can, I'll show you.

This excerpt reflects a pattern that was common across both schools, of students using mobile phones or MP3 players to introduce their liked music into class. The use of these devices was not barred by teachers but managed, to allow students' music choices to be part of the lesson.

The following excerpt (from a lesson with about a dozen Year 10 students in School B) shows some of the explicit negotiation about the status of mobile phones and/or MP3 players:

Lauren: For the first bit, the first half hour, I'm gonna let you crack on with whatever you need to do, whether it's recording or whatever.

[Alan gets phone out of his shirt pocket]

Lauren: Put that away

[Alan puts phone back in shirt pocket]

Kenny: Should confiscate it

Lauren: Yep. Put it away or it's gonna go

Alan: Or what

Later in the lesson:

Lauren [to Terry]: Go and find your original [Cubase file], get yourself a dongle. 
Terry walked out, looking at his phone/MP3 and thumbscrolling the touchscreen. Shortly after he walked back in and sat back at the computer. Lauren said to him:

Lauren: Put that phone away

Terry: 's not a phone. It's used for both

Lauren: What is it then?

Terry: 's an ipod

Lauren: OK well

Terry [defensively]: 's OK isn't it

Lauren: It's OK for us in Music, but if someone comes in they could try to take it off you, so better hide it.

This was before lunch. The lesson continued after lunch; when the lesson had almost ended, many students were logging off the computers and getting ready to go, some doing things with their phones. A younger student came into the room (Year 8), saw the phones, and asked "Miss how come you don't confiscate it?", to which Lauren replied:

Lauren: No it's Music here, I have been doing, it's last minute. [.] It's Music, we do it a bit different, they use it for their coursework. [.] You wouldn't do it in English, you'd get it confiscated straight away [.] but this it's Music it's a bit different.

The earlier negotiation about ipod-vs-phone, and the teacher's response to the young student's question, show the active negotiation of the possible boundaries between authorised and unauthorised, as well as between phone and MP3 player. The teacher's reponse to the question shows a motivation to uphold the general rule against mobile phone use ("I have been doing [...] You wouldn't do it in English") while explaining the apparent contradiction, through two possibly contradictory justifications: either by saying the infraction is minor ("it's last minute") or that phones are allowed in music lessons ("It's Music, we do it a bit different, they use it for their coursework" - though in this instance the phones aren't being used for coursework).

The next excerpt is from the same class group but a few weeks later, in which the class has been set a task to come up with some TV/radio publicity, including appropriate music. The excerpt illustrates further the way phones are pushed to either side of the authorised/unauthorised divide according to subtle local factors:

Kenny was sitting at his computer, with an empty word doc in front of him. He had a touchscreen phone in his hand and was scrolling through something.

Lauren: Right put that away

Kenny: You can't see me I can't see you

Lauren: Yeah I can, put it away

Kenny: You can't see me I can't see you

Terry: Miss he's looking for the Rock Star image look it's there

Terry reached over and pointed at something on the phone screen. Kenny shook the phone a bit (not sure why). 
Lauren: You can do that on the Internet

Kenny: I'm trying

Lauren: Put it away

Terry: Alright I'll pocket it

Terry took the phone off Kenny and put it away in his shirt pocket. (I think the phone probably belonged to Terry.)

Shortly after, Kenny got his Blackberry phone out and earphones. He played a track back, out loud (not through the earphones). Kenny sang along to it a bit, then stopped the track. Then he restarted it. As it continued to play:

Philip: What you're not using that are you?

Kenny: Yeah

While playing the track he scrolled down on the Blackberry screen.

Kenny: Oh my god I found it

He played back the first few seconds of a track which started with a vocal note "ahhhhhhh", then stopped it. Shortly after he played a third track from his Blackberry, a grime-type track with urban beats and a male vocal. He wrote a line of text in his word document.

Kenny: I'm doing a ravey thing

Lauren came over to Kenny and read what he'd written, then laughed.

Lauren: What's that, a rave, like so where is it taking place?

Kenny: In a bedroom

Lauren: In a bedroom? Two guys having a rave in a bedroom?

Kenny: Yeah

Meanwhile, Keane got up and went over to the group opposite - he gave one student an earphone from his phone and played him something.

Keane: Downloaded it last night bruv. I was trying to get to sleep I was just like, [grins, dances]

In this excerpt mobile phones are permitted as part of the lesson activity, but still there is subtle negotiation needed to keep activity within the realm of what the teacher wants. There appear to be engagement benefits for the students in bringing their own social music practices into the activity. Further, these practices which the students can bring into the classroom are good ways to facilitate the music sharing that is at the heart of many discussions in music lessons. We observed many occasions in which students used their earphones with their phones / MP3 players to share music privately with others. The above excerpt includes playing music out loud, which can sometimes be considered disruptive (and censured by the teacher) but not always, and not in this case.

Many schools operate "blanket bans" on mobile phones (mentioned for example in Savage [2010]), but according to our observations these are not quite what they seem. Irrespective of the possibility that school administrations should adopt a more nuanced policy on mobile phones (a debate for the schools themselves), these devices are found in school music lessons in an interesting state of 
fluidity regarding their authorised/unauthorised status, since they are a useful vehicle for bringing some informal music practices into class. Both teachers and students make use of this fluidity. As Baxter [2009, p. 62] notes, "The challenge for the music teacher is to keep abreast of such developments and to find ways of utilizing them for positive means, thus continuing to build the bridge between out of school and in school."

\section{Youtube}

One of the most heavily-used technologies in the classes we observed was Youtube. ${ }^{1}$

Youtube's breadth of coverage appears to be what supports its thorough integration into classroom practice: students and teachers often searched in Youtube without having checked in advance they would find something relevant, and almost always found a video which satisfied them. Youtube was used by teachers and by students for many purposes. We observed uses including:

- Playing a song to support a lesson topic (e.g. to demonstrate a musical style)

- Playing documentaries about musical topics

- Playing examples of live performance

- Playing a track to work out its chords and/or instrumentation

- Playing a "with-lyrics" video of a track (showing animated lyrics rather than a music video), to work out or sing along to the lyrics

- Playing a track to perform along to (playing instruments and/or dancing)

- Playing back old TV/radio adverts (to demonstrate the use of music in them)

- Playing background music quietly

- Finding sound effects or soundtrack elements whose audio could be ripped and used

- Music sharing (playing liked music to others)

There was a strong overlap between teachers' and students' initation of Youtube for these uses, and a strong overlap in whether the projected screen or a student's individual screen was used for playback.

Contrary to the suggestions made by Webb [2007], Youtube usage was generally not oriented around carefully-planned and -structured video-based activities, but as a resource casually integrated into many multimodal activities. (Another resource we saw often used, and treated in the same way, was Wikipedia.)

\footnotetext{
${ }^{1}$ Here we do mean Youtube specifically, and not video or Internet video more generally. There was some non-Youtube use of video, but to a much smaller extent, and it lacked some of the features which we discuss herein.
} 
Youtube (as Wikipedia) has the important features of very broad coverage plus a good free text search, allowing teachers and students to use it at short notice without having to consider in advance whether material will be found.

Indeed, Youtube's broad coverage even within the music domain often makes it the most reliable source of material, as demonstrated in this excerpt in which some Year 8 students and two teachers go to the web to find the chords for a song they want to play:

The group went from the studio through to the Music Office (led by Andy) to play back a song to learn. They went to teacher Evan's desk, where Evan was sitting at his laptop, and asked him to play a song. He was initially using Spotify to search for the song.

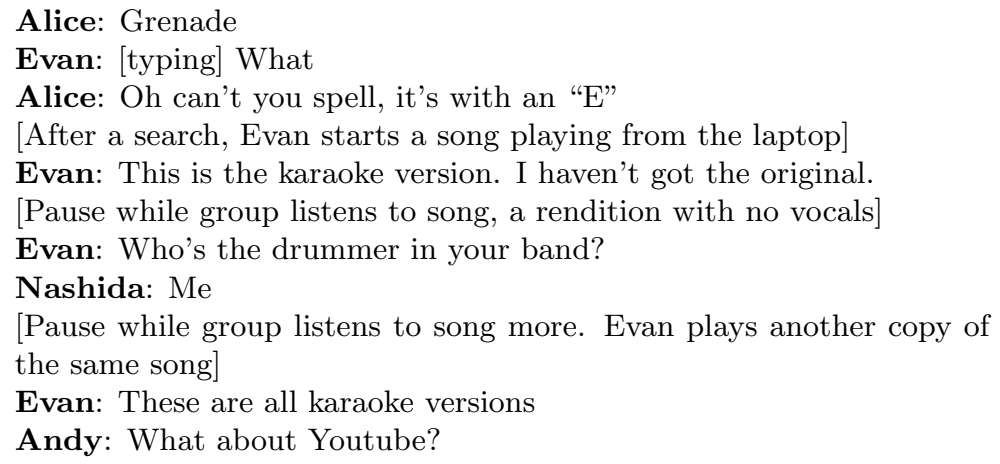

Evan searched for the song on Youtube, and played it back - this time the original version with vocals. Evan and Andy discussed what the chords were in the song - were they the same all the way through? Was it a "loop"?

Andy: The verse is OK but the chorus is a bit tricky

Evan: Dyou want the chords printed out?

Andy: Yes please sir

Evan searched for the chords using Google, finding a satisfactory result on a website.

Evan: Verse is just D minor A minor

Andy: OK

Evan: Chorus is D minor B flat F C.

Andy: Mmm

Evan: You could do an arrangement of it

Andy: Yeah

In this excerpt the teacher Evan starts with Spotify. No-one explicitly says why the karaoke versions retrieved are unsatisfactory - possibly because it's less obvious how the music fits with the words, possibly because they might not be faithful to the original. The principal issue discussed is the chord sequence, which one might think would be evident in the karaoke versions. Whatever the reason, in this case Youtube rather than Spotify is the destination for the successful search for music playback. This is followed by a generic web search 
for chord information, a type of information for which the teachers/students don't reach for Youtube.

The above excerpt featured the use of Youtube on the small screen (though as a group activity). All classrooms studied featured a projector screen (an interactive whiteboard [IW]) at the front of the room, and these too were often used for showing Youtube videos. One might assume that video on the projected screen is used primarily by teachers for presenting content to the whole class, while students' video use happens on the small screen. In a different context, Shannon and Cunningham [2009] explore the subtle design factors which can reinforce this division, despite the fact that IWs can be used for multi-party at-screen activities. However, in our study we witnessed many occasions when students used the large screen, sometimes to show something to a large class group but often just because of the conveniently visible screen and/or the loudspeakers attached to that computer. The following excerpt takes place during a Year 10 class at School B, with the class divided into groups each learning to play/sing a specific pop song. Most groups had been led out to practice rooms, and one group of five students remained in the main classroom:

Amy, sitting at the classroom computer, opened the web browser to reveal a Youtube page with a samba video on it (from the previous lesson). This was visible on the projected screen as well as on the monitor she was looking at. She searched for something then clicked through to "Coldplay - Clocks (with lyrics)" and played this video. It played the original song over the speakers while the video (embedded in the Youtube page) showed a blue box with the lyrics appearing in blocks of white text.

Two students (Toby and Jo) came in with electric bass and electric guitar respectively, and an amp each. They set up their equipment in the corner to my right. The group of students was thus:

- Andrew: sitting at electric piano

- Amy: sitting at the classroom computer

- Toby: sitting with electric bass guitar

- Jo: standing with electric guitar

- Donna: sitting perched on desk across the room (near Amy)

Toby and Jo started playing along to the music that was playing on the Youtube video, as did Andrew on the electric piano.

Corinne (the teacher) came in. Andrew played the main progression from "Clocks" a bit more, then went out of the room with Corinne. Toby and Jo carried on playing it for a bit. Then Jo leant over to Toby to point at a fret on his guitar, telling him to play it (possibly she was showing him what note to play in the bridge). The video on the screen continued to play.

Corinne came back in and told the group to get on because they were going to be assessed. Donna indicated the Youtube video on the IW screen and said:

Donna: I'm looking at the words

[Corinne walks towards the door]

Corinne to Donna: You need to be by the computer

Donna: I can see it from here

[Corinne exits] 
Toby and Jo were playing the main chord progression from the song again, while the Youtube video was playing back. At one point:

Jo to Toby: Then it goes to the bridge [plays bridge chords]

By this point the Youtube video and Toby/Jo were not playing in time; Amy (sitting at the computer) would occasionally rewind the video, so although Toby/Jo were playing the same song, at this point they were overlapping rather than playing in sync with it.

Corinne came back in and got Donna to sit with her and Amy at the computer. She restarted the Youtube video, encouraging them to sing the words. Toby and Jo played in sync with the video. Amy or Donna might have sung along, but not audibly (from across the room). After a bit Corinne went to the door again and called:

Corinne: Right guys?

[Toby and Jo stop playing]

Corinne: After this time through we're gonna stop the video, you're gonna do it through with the lyrics but no backing. Alright?

Amy: Miss the lyrics are at home miss. Miss the lyrics are at home miss.

Corinne: No they're not. [Points at projector screen] On the screen. [Corinne exits]

Toby and Jo resumed playing along to the Youtube video. When the song reached the bridge Toby stopped playing; Jo played the bridge chords and looked at Toby (as if to make eye-contact and/or get him to try the bridge notes). Toby got a bag of sweets out and ate some.

This excerpt shows Youtube used by the students as the source for lyrics and a track to play along to, part of a multimodal activity combining audio, lyrics and instruments. The musicians play to the video as a reference, but one singer occasionally rewinds the video in a way that clashes with the musicians' playing, exerting a slightly disruptive control.

The excerpt also shows some interaction between the big and small screen (both showing the same content), with the teacher requesting that the students sit by the small screen, while a student expresses a preference for sitting looking towards the projected screen - though specific reasons for these contrasting preferences are not evident.

This and the previous example show some of the many and varied uses that teachers and students make of Internet video, and how this is facilitated by the exhaustive one-stop shop that is Youtube. It is not just the availability of this video but its ease of retrieval (by text query) that enables these activities. The use of Youtube is in general quite different from that advocated by Webb [2007], who argues for designing tasks around a specific video. Instead, teachers and students often call up videos at short notice as part of ongoing discussions or tasks.

To summarise, we observed use of Youtube very strongly integrated into the music classroom in many ways, on the small screen and the large screen, deployed by both teacher and student. Youtube's advantage is not just the 
provision of on-demand video, but its extremely broad library of content and good text search, allowing for ad hoc use within a class activity. Along with mobile phones and MP3 players, it is a convenient route for connecting with informal listening practices, allowing students to bring their own preferred musics into discussion. This usage probably aligns very well with students' use outside school, although we did not investigate this ourselves. See for example Cunningham and Nichols [2008], who studies a cohort of undergraduate students, finding that Youtube is the dominant use of Internet video in many situations, and that the text search is the most important route in to watching videos.

We note that Savage's 2010 survey of ICT usage in secondary schools does not make mention of these modes of ICT use. Youtube is a free web-based service, and so does not appear in a list of ICT purchases. However, it (and other services such as Wikipedia) should not be overlooked for their role in current music educational practice. Nor should they be omitted from critical discussion of the influence of single large commercial providers on music education. Heavy reliance on a single provider does bring dangers, such as being dependent on the availability and the whims of that provider. This is true even if the provision is not through direct purchase.

However, having emphasised the role of specific recent technologies in the modern music classroom, we next wish to place them more clearly in their multimodal context.

\section{Multimodality: high- and low-tech together}

Discussion of technology often focusses on the most recent hi-tech innovations, since they are an area of conspicuous change. Much of our own discussion thus far has had this focus. However, in our study we found a consistent pattern of untroubled integration of a wide range of different modalities with each other, in many different configurations. This included ICT but also posters, felt-tips, post-it notes, mime, singing and more. We have highlighted mobile phones and Youtube in the present paper, but their roles as learning resources was not different in kind to the lower-tech or more traditional resources. Generally, they were one of the rich array of resources available in the music classroom that could be drawn upon at short notice.

Examples of this were seen in Sections 3 and 4: for example when students combined a phone with a microphone and speaker to play music back, or when students played a Youtube video on the IW screen, and used instruments and singing to play along with it.

Various resources could often lie latent for a long time, and be called up at short notice. We observed this in the case of posters: many music classrooms had music-themed posters around the walls, and for weeks we saw no interaction with them at all. One might have concluded they had become unnoticed background for the teachers and students. Then one day, a conversation about composers brought a poster into direct use (in fact it was pulled off the wall and laid on a table). Posters are a type of resource which, like Internet-based resources, allow 
for this latency because their maintenance cost is extremely low.

We consider the issue of multimodality in this study further in a separate work [submitted]. (See also Kress et al. [2006, esp. Chapter 2] on the thoroughgoing multimodality in a school science lesson.) Here we note that both highand low-technology appeared to be well-integrated in the classes we observed. Unlike previous studies [Lamont et al., 2003, Savage, 2010] we saw no particular evidence of teachers' lag in ICT skills, which might act as a brake on successful integration. However, there may have been an element of self-selection of technologically confident schools in our study so we do not propose to generalise this particular point.

\section{Conclusions}

In this paper we have discussed technologies more commonly associated with informal music practices and their current place in the music classroom, from the perspective of an ethnographic study in two London secondary schools. In particular we have discussed mobile phones and MP3 players, and Youtube. Note that we did not deliberately seek out these particular technologies to analyse, rather their importance in the music classroom context arose from the observations.

In particular, Youtube appeared to be well-integrated into music lessons, used by both teachers and students for a variety of purposes. Youtube offers a very broad library of video, including music videos but also many other relevant resources, and a powerful text search which teachers and students use to access video without extensive prior planning.

We also observed use of students' own mobile phones and MP3 players. Their main role, when authorised, was to bring students' liked music into the classroom.

However, we emphasise that individual technologies cannot be considered in isolation: most teaching and learning activities recruit a range of available technologies and modalities, and the ones we have focussed on are but part of the array of resources that both teachers and students deploy. These technologies do not appear on the list of schools' ICT purchases but form an increasingly important part of the ecosystem.

The Henley Review of Music Education in England [Henley, 2011] argued for the need to "develop a national plan for the use of technology in the delivery of Music Education" (Recommendation 33). Plans of this type should accommodate not only schools' formalised ICT systems (such as Virtual Learning Environments or specific bought-in software), but also the wider environment of Internet-based services, and the technologies used by teenagers and others for informal music experiences. They should also avoid rigidity in prescribing how technology could or should be used, allowing for teachers' and students' abilities to combine and adapt many different technologies into their everyday activities. 


\section{References}

A. Baxter. The mobile phone and class music: A teacher's perspective. In J. Finney and P. Burnard, editors, Music Education with Digital Technology, pages 52-64. Continuum, 2009. ISBN 0826420710.

S. J. Cunningham and D. M. Nichols. How people find videos. In Proceedings of the 8th ACM/IEEE-CS Joint Conference on Digital libraries, pages 201-210, New York, NY, USA, 2008. doi: 10.1145/1378889.1378924.

R. M. Emerson, R. I. Fretz, and L. L. Shaw. Writing ethnographic fieldnotes. Chicago guides to writing, editing, and publishing. University of Chicago Press, 1995. ISBN 0-226-20681-5.

G. Folkestad. Here, there and everywhere: music education research in a globalised world. Music Education Research, 7(3):279-287, Nov 2005. ISSN 14613808. doi: $10.1080 / 14613800500324390$.

L. Green. Music, informal learning and the school: A new classroom pedagogy. Ashgate Pub Co, 2008. ISBN 075466242X.

L. Green. Response [to special issue informal learning in music education]. British Journal of Music Education, 27(01):89-93, 2010. ISSN 0265-0517. doi: $10.1017 / \mathrm{S} 0265051709990222$.

S. Hallam, A. Creech, C. Sandford, T. Rinta, and K. Shave. Survey of Musical Futures. Technical report, Institute of Education, University of London, 2008. URL http://media.musicalfutures.org.uk/documents/resource/ 27229/IOE_Musical_Futures_report.pdf.

D. Henley. Music education in England - A review. Technical Report DFE-00011-2011, Department for Education and the Department for Culture, Media and Sport, Feb 2011. URL http://www.education.gov.uk/ publications/standard/publicationDetail/Page1/DFE-00011-2011.

G. Kress, T. Charalampos, C. Jewitt, and J. Ogborn. Multimodal teaching and learning: The rhetorics of the science classroom. Continuum, 2006. ISBN 0826481728 .

A. Lamont, D. J. Hargreaves, N. A. Marshall, and M. Tarrant. Young people's music in and out of school. British Journal of Music Education, 20(03):229241, 2003. ISSN 0265-0517. doi: 10.1017/S0265051703005412.

Nielsen Company. How teens use media: A Nielsen report on the myths and realities of teen media trends. Technical report, Jun 2009. URL http://blog.nielsen.com/nielsenwire/reports/nielsen_ howteensusemedia_june09.pdf.

N. Orio. Music retrieval: a tutorial and review. Foundations and Trends in Information Retrieval, 1(1):1-90, Nov 2006. doi: 10.1561/1500000002. 
J. Savage. A survey of ICT usage across english secondary schools. Music Education Research, 12(1):89-104, 2010. ISSN 1461-3808. doi: 10.1080/ 14613800903568288. URL http://jsavage.org.uk/wp-content/uploads/ 2011/03/ict_usage_DRAFT.pdf.

G. Shannon and S. J. Cunningham. Impact of classroom design on interactive whiteboard use in a special needs classroom. In Proceedings of the 10th International Conference NZ Chapter of the ACM's Special Interest Group on Human-Computer Interaction, pages 1-4. ACM, 2009. doi: 10.1145/1577782.1577783.

M. Webb. Music analysis down the (You) tube? Exploring the potential of crossmedia listening for the music classroom. British Journal of Music Education, 24(02):147-164, 2007. ISSN 0265-0517. doi: 10.1017/S0265051707007401.

R. Wright, editor. British Journal of Music Education, Special Issue 01 (Informal Learning in Music Education), volume 27. Cambridge Univ Press, 2010. 